\title{
Deterministic processes drive functional and phylogenetic temporal changes of woody species in temperate forests in Northeast China
}

\author{
Shuai Fang ${ }^{1,2} \cdot$ François Munoz $^{3} \cdot \mathrm{Ji} \mathrm{Ye}^{1} \cdot$ Fei Lin $^{1} \cdot$ Zuoqiang Yuan $^{1} \cdot$ Xu Kuang $^{4} \cdot$ Zhanqing Hao $^{1} \cdot$ Xugao Wang $^{1}$
}

Received: 24 June 2018 / Accepted: 27 March 2019 / Published online: 23 April 2019

(C) INRA and Springer-Verlag France SAS, part of Springer Nature 2019

\begin{abstract}
- Key Message Deterministic processes drive functional and phylogenetic temporal changes of woody species in temperate forest, depending on successional stage and tree size classes. The dominant influential factors changed from abiotic (especially topographic factors) to biotic (e.g., basal area), with both increasing successional stage and tree size, suggesting that deterministic processes shifted from habitat filtering to biotic interactions.

- Context Disentangling how deterministic and stochastic processes govern the temporal change of community composition is critical for understanding community assembly and predicting long-term ecosystem change. However, rare studies have examined the distinctive imprint of these two processes on functional and phylogenetic temporal changes of woody species in temperate forests.

- Aims The objectives of this study are to detect (1) the relative importance of deterministic vs. stochastic process in driving the functional and phylogenetic temporal changes at different successional stages and tree size classes in temperate forests and (2) the relative influence of abiotic vs. biotic factors on temporal change.

- Methods We analyzed 10 years of detailed species composition, phylogenetic information, and 14 functional traits from 66 woody species in young-growth (5-ha) and old-growth (25-ha) forest plots in Northeast China. We devised a null model approach to determine the relative importance of deterministic and stochastic processes in driving functional and phylogenetic temporal changes. Then, we investigated the influence of abiotic (soil and topography) and biotic (basal area, stem density, and species richness) factors on temporal change using boosted regression tree (BRT) models. All analyses were conducted for different tree sizes (all trees, small trees [diameter at breast height $(\mathrm{DBH})<10 \mathrm{~cm}]$, and large trees $[\mathrm{DBH} \geq 10 \mathrm{~cm}]$ ).
\end{abstract}

Handling Editor: Laurent Bergès

Contribution of the co-authors S.F. and X.W. conceived of the ideas. S.F., X.W., and F.M. designed the study. S.F., X.W., Z.Y., J.Y., F.L., X.K., and Z.H. collected the field data. S.F. analyzed the data. S.F., X.W., and F.M. led the writing. All authors contributed critically to the drafts and gave the final approval for publication.

Electronic supplementary material The online version of this article (https://doi.org/10.1007/s13595-019-0830-2) contains supplementary material, which is available to authorized users.

Xugao Wang

wangxg@iae.ac.cn

1 Key Laboratory of Forest Ecology and Management, Institute of Applied Ecology, Chinese Academy of Sciences, Shenyang 110016, People's Republic of China

2 University of Chinese Academy of Sciences, Beijing 100049, People's Republic of China
3 Laboratoire d'Ecologie Alpine, Universite Grenoble Alpes, Grenoble, France

4 Henan Province Key Laboratory of Water Pollution Control and Rehabilitation Technology, Henan University of Urban Construction, Henan, People's Republic of China 
- Results In young-growth forest, functional and phylogenetic temporal changes were basically higher than expected for all trees, small trees, and large trees. Conversely, in the old-growth forest, functional and phylogenetic temporal changes were lower than expected for all trees, but opposite patterns were found for two size classes; i.e., change was higher than expected for large trees and lower than expected for small trees. BRT models showed that the most influential factors underlying the temporal change of all trees shifted from abiotic (e.g., topography) to biotic (e.g., basal area) factors with increasing succession stage. Regardless of successional stage, the relevant factors changed from abiotic factors for small trees to biotic factors for large trees.

- Conclusion Deterministic processes govern tree functional and phylogenetic temporal changes, and the underlying deterministic processes change from habitat filtering to biotic interaction over succession and with increasing tree size.

Keywords Deterministic process $\cdot$ Functional trait $\cdot$ Phylogeny $\cdot$ Size class $\cdot$ Succession $\cdot$ Temporal change

\section{Introduction}

Temporal change in community composition results from a combination of immigration and local demographic dynamics (Magurran and Henderson 2010). The dynamics depend on stochastic processes and on how survival and reproduction are affected by environmental factors and biotic interactions over time (Hubbell 2001; Legendre and Gauthier 2014; Shimadzu et al. 2015). Characterizing the temporal change of community composition can thus provide insights into underlying assembly processes (Dornelas et al. 2013; Swenson et al. 2012). Many studies in community ecology aim at inferring assembly processes from the spatial structure of communities at a given time (Dray et al. 2012), but they miss how composition at a given time can influence subsequent dynamics, especially when biotic interactions are at play. Although space-for-time substitution (chronosequence) considers different temporal stages of community dynamics distributed in space, it does not acknowledge how assembly depends on previous community states ( $\mathrm{Li}$ et al. 2015). Therefore, longitudinal data are needed to ravel out the mechanisms governing the temporal change of community composition (Dornelas et al. 2013).

With longitudinal data, quantifying the functional or phylogenetic temporal change relative to species change provides important insights into two basic types of mechanisms: deterministic and stochastic processes (Cadotte et al. 2011; Gianuca et al. 2017; Stegen et al. 2013; Swenson 2013). Stochastic processes entail random temporal change patterns, while deterministic, niche-based processes can constrain functional and phylogenetic change patterns to be nonrandom (Adler et al. 2013; Götzenberger et al. 2012; Jabot et al. 2018; Letten et al. 2014). Along ecological succession, communities undergo a joint influence of deterministic and stochastic processes, thus providing an ideal context to investigate the mechanisms underlying community temporal change (Connell and Slatyer 1977; Lohbeck et al. 2014; Meiners et al. 2015). It is expected that deterministically driven succession should directionally move communities towards changing functional composition over time, until some steady composition is reached (Alday et al. 2011; Li et al. 2016), while temporal change would not deviate from random under the sole influence of stochastic processes. Phylogenetic change should also be influenced by deterministic processes, because phylogenetic composition reflects adaptations shared in evolutionary history (Cadotte et al. 2013; Gerhold et al. 2015; Mouquet et al. 2012; Webb et al. 2002). Recent successional studies in tropical forest and heathland have quantified functional or phylogenetic temporal changes and shown prevalence of deterministic processes (Cequinel et al. 2018; Letten et al. 2014; Swenson et al. 2012). However, there is little evidence on how deterministic processes influence temporal functional and phylogenetic changes over succession in temperate forests.

Processes acting on the establishment and persistence of older and taller trees can differ from those influencing young recruits and understory trees. Different or nonrandom patterns across size classes should then provide insights on the mechanisms underlying temporal change over succession (Baldeck et al. 2013; Lasky et al. 2015; Rüger et al. 2012). First, at early successional stage, while pioneer trees may still dominate the canopy, recruitment of distantly related late-successional species may entail greater functional and phylogenetic temporal changes among small trees (Anderson 2007; Norden et al. 2012). Later on, the temporal change of both small and large trees should become lower if a steady functional or phylogenetic composition is reached. Second, the influence of biotic interactions is expected to increase over time, and the recruited trees reaching the canopy should be more dissimilar from established trees in order to persist (Yang et al. 2014). Such limiting similarity should thus increase temporal change among large trees (Swenson et al. 2007; Wang et al. 2015). Third, habitat filtering should basically play at earlier life stages and be stronger in the shady understory, which entails a lower temporal change of small trees ( $\mathrm{Li}$ et al. 2018). Since large trees are established in suitable micro-habitats after filtering occurred, their survival is more influenced by biotic neighborhood (Wang et al. 2012). Thus, we can also expect that the driving forces underlying temporal change may change from abiotic to biotic from smaller to larger trees.

In this study, based on 10 years of detailed species composition data, combined with 14 functional traits and phylogenetic information of 66 woody species, we aimed to determine 
the drivers of functional and phylogenetic temporal changes of woody species in a temperate forest ecosystem. We selected two permanent forest plots, which represented earlier $(\sim 80$ years $)$ and later $(\sim 300$ years $)$ successional stages. We examined the temporal change and underlying drivers at different tree sizes (all, small [diameter at breast height $(\mathrm{DBH})<10$ $\mathrm{cm}]$, and large $[\mathrm{DBH} \geq 10 \mathrm{~cm}]$ trees) and asked the following two questions: (1) Are deterministic or stochastic processes more dominant in driving community functional (all traits together and for different trait dimensions) and phylogenetic temporal changes at different successional stages and size classes? (2) How do abiotic and biotic factors influence temporal change at different successional stages and size classes?

\section{Materials and methods}

\subsection{Study sites}

Our study area is located in Changbai Nature Reserve, which is one of the largest biosphere reserves in China $\left(42^{\circ} 23^{\prime} \mathrm{N}\right.$, $128^{\circ} 05^{\prime} \mathrm{E}$ ) (Hao et al. 2007). The mean annual precipitation is approximately $700 \mathrm{~mm}$, which mostly occurs from June to September (480-500 $\mathrm{mm})$. The mean annual temperature is $2.8^{\circ} \mathrm{C}$, with a January mean of $-13.7^{\circ} \mathrm{C}$ and a July mean of 19.6 ${ }^{\circ} \mathrm{C}$ (Yang et al. 1985).

We surveyed two large permanent forest plots: one of 5-ha area $(250 \mathrm{~m} \times 200 \mathrm{~m})$ and the other of 25 -ha area $(500 \mathrm{~m} \times 500$ $\mathrm{m})$, located in the core zone of Changbaishan (CBS) Nature Reserve. The 25-ha forest plot represents a mature forest without logging and other human disturbances for about 300 years, while the 5-ha forest plot is a younger-growth forest that was subject to logging until the 1930s; i.e., it is a well-established secondary forest. Censuses for the 25-ha old-growth forest plot were carried out in 2004, 2009, and 2014, while the 5-ha young-growth forest plot was surveyed in 2005, 2010, and 2015. In each plot, all free-standing woody stems with a DBH $\geq 1 \mathrm{~cm}$ were identified, tagged, and mapped (Table 1). We divided the old-growth forest plot into $62520 \mathrm{~m} \times 20 \mathrm{~m}$ quadrats and the young-growth forest plot into $12020 \mathrm{~m} \times 20 \mathrm{~m}$ quadrats (excluding a few smaller quadrats). The average number of species of all quadrats was 11.5 in the old-growth forest plot and 17.5 in the young-growth forest plot. Overall, we selected 66 species for which functional trait data were available. These species belonged to 40 genera and 20 families.

\subsection{Functional traits}

We measured 14 functional traits of 66 species representing basic morphological and ecophysiological properties of leaf, stem, and root organs (Table 2) in both forest plots. Five to twenty individuals were selected for each species, and their values were averaged. The DBH of selected individuals were similar to the largest individual of each species in both plots. All trait measurements were conducted following PérezHarguindeguy et al. (2013). More detailed information on trait measurement is available in Appendix S1.

\subsection{Functional dendrogram}

We performed principal component analysis (PCA) with varimax rotation to define independent functional dimensions (Díaz et al. 2016). We then calculated trait Euclidean distances based on the species scores on the first nine principal components (explaining a $>90 \%$ variation of the total variance in traits). Finally, the distance matrix was transformed to a functional dendrogram by hierarchical clustering, which had a similar data structure to phylogenetic tree and could be analyzed with a concurrent method (Petchey and Gaston 2007).

We used species scores on the first three principal components to represent primary trait dimensions (explaining a > $60 \%$ variation of the total variance in traits) (Laughlin 2014; Westoby et al. 2002). The first axis (RC1) represented the leaf economic spectrum from a more acquisitive strategy (high leaf nitrogen, leaf phosphorus content) to a more conservative strategy (high dry matter content). The second axis (RC2) reflected the wood economic spectrum from tall to short and low to high wood density species. The third axis (RC3) captured the variation in root traits, which indicated the variation of species nutrition absorption ability (Appendix S2) (KramerWalter et al. 2016; Reich 2014). Functional dendrogram was calculated for each trait dimension separately.
Table 1 Summary information of the 5-ha young-growth forest plot and the 25-ha old-growth forest plots

\begin{tabular}{|c|c|c|c|c|c|c|}
\hline Plot & Year & Species & $\begin{array}{l}\text { Mean } \\
\text { DBH }(\mathrm{cm})\end{array}$ & $\begin{array}{l}\text { Individual } \\
\text { number }\left(\mathrm{ha}^{-1}\right)\end{array}$ & Mortality & Recruitment \\
\hline \multirow{3}{*}{$\begin{array}{l}\text { 25-ha old-growth } \\
\text { forest plot }\end{array}$} & 2004 & 52 & 10.88 & 1470 & \multirow[t]{3}{*}{$10.7[1.5,9.2]$} & \multirow[t]{3}{*}{$7.3[1.0,7.3]$} \\
\hline & 2009 & 51 & 11.54 & 1402.5 & & \\
\hline & 2014 & 52 & 11.54 & 1385.2 & & \\
\hline \multirow{3}{*}{$\begin{array}{l}\text { 5-ha young-growth } \\
\text { forest plot }\end{array}$} & 2005 & 53 & 7.46 & 3447.5 & \multirow[t]{3}{*}{$28.8[5.0,23.8]$} & \multirow[t]{3}{*}{$21.9[5.6,21.9]$} \\
\hline & 2010 & 50 & 8.17 & 3195 & & \\
\hline & 2015 & 54 & 7.93 & 3260 & & \\
\hline
\end{tabular}

The mean frequency of mortality and recruitment events was based on a $400-\mathrm{m}^{2}$ quadrat. The mean frequency for all trees and two size classes [large, small] is provided 
Table 2 Phylogenetic signal (Blomberg's $K$ value) of 14 functional traits for 66 species from the 5-ha young-growth forest plot and the 25-ha old-growth forest plot

\begin{tabular}{|c|c|c|c|}
\hline \multirow[t]{2}{*}{ Organ } & \multirow[t]{2}{*}{ Functional trait } & \multicolumn{2}{|l|}{ Blomberg's $K$ value } \\
\hline & & $\begin{array}{l}\text { 5-ha young-growth } \\
\text { forest plot }\end{array}$ & $\begin{array}{l}\text { 25-ha old growth } \\
\text { forest plot }\end{array}$ \\
\hline \multirow[t]{9}{*}{ Leaf } & Leaf dry matter content (LDMC; \%) & $0.05[0.11]$ & $0.06[0.12]$ \\
\hline & Specific leaf area (SLA; $\mathrm{cm}^{2} \mathrm{~g}^{-1}$ ) & $0.64[0.96]$ & $0.64[0.99]$ \\
\hline & Leaf area $\left(\mathrm{LA} ; \mathrm{cm}^{2}\right)$ & $0.29[0.30]$ & $0.20[0.24]$ \\
\hline & Leaf carbon content $\left(\mathrm{LCC} ; \mu \mathrm{g} \mathrm{g}^{-1}\right)$ & $0.98[0.61]$ & $0.66[0.50]$ \\
\hline & Leaf nitrogen content ( $\left.\mathrm{LNC} ; \mu \mathrm{g} \mathrm{g}^{-1}\right)$ & $0.56[0.48]$ & $0.52[0.49]$ \\
\hline & Leaf phosphorus content (LPC; $\left.\mu \mathrm{g} \mathrm{g}^{-1}\right)$ & $0.32[0.42]$ & $0.35[0.36]$ \\
\hline & Leaf potassium content $\left(\mathrm{LKC} ; \mu \mathrm{g} \mathrm{g}^{-1}\right)$ & $0.43[1.33]$ & $0.51[1.17]$ \\
\hline & Leaf $\delta^{15} \mathrm{~N}$ composition $(\mathrm{N} 15 ; \% o)$ & $0.24[0.42]$ & $0.27[0.46]$ \\
\hline & Leaf $\delta^{13} \mathrm{C}$ composition $(\mathrm{C} 13 ; \% o)$ & $0.29[0.55]$ & $0.24[0.46]$ \\
\hline \multirow[t]{2}{*}{ Stem } & Trunk bark thickness (ABT; mm) & $0.29[0.49]$ & $0.30[0.49]$ \\
\hline & Wood density (WD; $\mathrm{mg} \mathrm{cm}^{-3}$ ) & $0.55[0.75]$ & $0.50[0.74]$ \\
\hline \multirow[t]{2}{*}{ Root } & Specific root length (SRL; $\mathrm{cm} \mathrm{g}^{-1}$ ) & $0.70[0.51]$ & $0.79[0.55]$ \\
\hline & Root diameter (RD; mm) & $1.09[0.54]$ & $1.76[0.60]$ \\
\hline \multirow[t]{4}{*}{ Whole plant } & Height $(H ; \mathrm{m})$ & $0.43[0.51]$ & $0.47[0.51]$ \\
\hline & $\mathrm{RC} 1$ (leaf dimension) & $0.31[0.70]$ & $0.35[0.62]$ \\
\hline & RC2 (stem dimension) & $0.39[0.95]$ & $0.42[0.63]$ \\
\hline & RC3 (root dimension) & $1.76[0.54]$ & $1.22[0.58]$ \\
\hline
\end{tabular}

Phylogenetic signal with a $p$ value $<0.05$ is given in italics. Phylogenetic signal based on the angiosperms only is provided in square brackets

\subsection{Phylogenetic tree}

We used Phylomatic (Webb and Donoghue 2005) to build a phylogenetic tree on the basis of the vascular plant megatree published by Zanne et al. (2014). Because there were few species within each genus in this temperate forest, the phylogenetic tree included only few polytomies, with a minor impact on phylogenetic calculation.

\subsection{Phylogenetic signal}

We calculated Blomberg's $K$ statistic to represent a phylogenetic signal for each functional trait and each of the three trait dimensions. Phylogenetic signal evaluated the extent to which trait similarity could be related to phylogenetic relatedness. $K$ $=0$ meant no phylogenetic signal, $K<1$ meant less similarity among close relatives, and $K>1$ indicated more similarity among close relatives than expected under Brownian motion. Here, we calculated the signal both for all species and for angiosperms only, using the "phylosignal" function in the picante R package (Blomberg et al. 2003; Kembel et al. 2010).

\subsection{Biotic and abiotic factors}

For each $20 \mathrm{~m} \times 20 \mathrm{~m}$ quadrat, we calculated basal area (BA), species richness (SR), and stem density (SD) at the beginning of a census interval as biotic factors (Canham et al. 2004; Cequinel et al. 2018; Zhang et al. 2015).

In addition, we measured eight variables representing the abiotic environment, namely five soil factors $(\mathrm{pH}$, organic matter, total $\mathrm{N}$, total $\mathrm{P}$, and total $\mathrm{K}$ ) and three topographic factors (elevation, slope, and aspect) within each $20 \mathrm{~m} \times 20$ m quadrat (see Appendix S3). Due to a correlation among soil variables, we performed PCA and selected the first two principal components accounting for more than $85 \%$ of total variance (Wang et al. 2012). The first component was associated with a gradient of soil nutrient availability, while the second reflected a variation in soil $\mathrm{pH}$.

\subsection{Data analysis}

We calculated abundance-weighted mean pairwise phylogenetic and functional distances to quantify the temporal change of composition (i.e., temporal beta diversity) in the same quadrats sampled over different years (Swenson et al. 2012). As the results were similar for different census intervals, we only show the result for the 10-year interval (2004-2014 for the 25-ha oldgrowth forest plot; 2005-2015 for the 5-ha young-growth forest plot) for simplicity. A null model approach was chosen to evaluate departures of observed temporal beta diversity from a null expectation of random composition change. The null model randomly reshuffled taxa labels across the tips of the phylogenetic tree and functional dendrogram 999 times. This approach 
maintained observed community composition while randomizing species phylogenetic relatedness and trait similarity (Gotelli 2000). Then, we calculated the standardized effect size (SES) of phylogenetic and functional changes, as the difference between observed values and the mean of 999 null values, divided by the standard deviation of the random values. A positive SES indicated higher observed temporal change, and a negative SES indicated lower observed temporal change than expected by chance (Swenson 2013). We tested whether there was a tendency of SES values in a set of communities to be higher or lower than null expectation by performing the Wilcoxon signed-rank test and comparing them to 0 (Bestová et al. 2018; Zhang et al. 2018). Above analyses were conducted to examine phylogenetic and functional changes (multivariate and each trait dimension) for all trees and for each size class. Here, we also quantified phylogenetic temporal change with angiosperms only and found it was similar to the results based on all species. Therefore, we focus on the results based on all species for simplicity.

To assess how the relative influence of abiotic and biotic factors on the functional and phylogenetic temporal changes depended on successional stages and size classes, we applied a machine learning method, i.e., boosted regression tree (BRT), which had been widely used in ecological research (Elith et al. 2008; Suo et al. 2016). This method has strong predictive performance without requiring prior assumptions on normality, homogeneity of variance, or weak collinearity among predictors. The setting of model parameters (learning rate, bag fraction, tree complexity, and the number of cross-validation folds) can influence the predictive performance of BRT models. Following Elith et al. (2008), we set the parameters for learning rate and bagging fraction at 0.005 and 0.5 , respectively. In order to ensure reliable model fit, we reduced the learning rate to 0.0025 when the requirement for 1000 models was not met. To avoid over-fitting, we ran alternative models by setting tree complexity at 1, 2, 3, and 4 and chose the simpler BRT model with smaller tree complexity, when the improvement of prediction error (PE) was less than $1 \%$ for more complex models (Appendix S8). For each BRT model, we repeated 50 times and averaged the results. The relative importance values were scaled as percentages. We also used partial dependence functions to examine impacts of an individual variable on the response after averaging out the effects of the additional explanatory variables (Appendix S6) (Elith et al. 2008). In addition, we calculated Moran's I spatial autocorrelation index of BRT residuals, which was not significant here.

\section{Results}

\subsection{Functional and phylogenetic temporal changes}

In the young-growth forest, both functional and phylogenetic temporal changes were higher than expected $(p<0.01)$, indicating that the temporal change in composition involved dissimilar species. In contrast, the functional change was lower than random $(p<0.01)$ in the old-growth forest, while the phylogenetic temporal change did not differ from the null expectation (Fig. 1; Appendix S5).

In the young-growth forest, the functional change of both tree size classes was higher than expected $(p<0.01)$. Interestingly, the phylogenetic temporal change did not follow the same trajectory and was higher than expected for small trees and lower than expected for large trees. In the old-growth forest, we found that phylogenetic and functional temporal changes were consistently higher than expected for large trees and lower than expected for small trees $(p<0.01)$ (Fig. 1; Appendix S5).

In the young-growth forest, we found that the temporal change of all trees was higher than expected for the stem trait dimension and lower than expected for the leaf dimension $(p<$ 0.01) (Appendix S5). This was consistent for the two size classes. Conversely, the temporal change differed between size classes along the root dimension: change was higher for small trees and lower for large trees. In the old-growth forest, the temporal change along all three dimensions was lower than expected for all trees $(p<0.01)$, but higher than expected for large trees and lower than expected for small trees $(p<$ 0.01) (Fig. 1; Appendix S5).

\subsection{Influence of abiotic and biotic factors on functional and phylogenetic temporal changes}

In the young-growth forest, topographical factors had the highest relative importance of $53.3 \%$ for the functional temporal change and $44.1 \%$ for the phylogenetic temporal change of all trees. Topographic factors (especially elevation) primarily influenced the temporal change along the three trait dimensions. In addition, biotic factors had a relatively strong influence on the functional temporal change along the stem dimensions (49.1\%). Soil factors had relative importance of $28.7 \%$ for the functional temporal change along root dimensions (Fig. 2).

In the old-growth forest, biotic factors had the highest influence on functional and phylogenetic changes of all trees $(71.4 \%$ and $60.5 \%)$. Basal area was the most important biotic factor (34.2\% and $30.4 \%$ ) and positively influenced functional and phylogenetic changes (Fig. 2; Appendix S6). The functional temporal change along the leaf and root dimensions was more influenced by biotic factors with $48.1 \%$ and $41.6 \%$ and showed a unimodal pattern with basal area (Fig. 2; Appendix S6). However, the temporal change along the stem dimension was more driven by topographic factors with an influence of $46 \%$ (Fig. 2).

In both young-growth and old-growth forests, we found that the influence of abiotic factors on functional change decreased (especially for topographic factors, from 67.3 to $28.8 \%$ in the young-growth forest) and that of biotic factors increased (from 22.9 to $48.4 \%$ in the old- 
Fig. 1 Kernel density plot of standard effect size (SES) of abundance-weighted mean pairwise functional and phylogenetic distances in the 5-ha younggrowth forest plot (left, 20052015) and in the 25-ha old-growth forest plot (right, 2004-2014). Vertical red dash line represents the zero value of $x$-axis. All traits, first nine components of PCA based on all traits. Phylogeny, phylogenetic distances. RC1, leaf trait dimension. $\mathrm{RC} 2$, stem trait dimension. $\mathrm{RC} 3$, root trait dimension

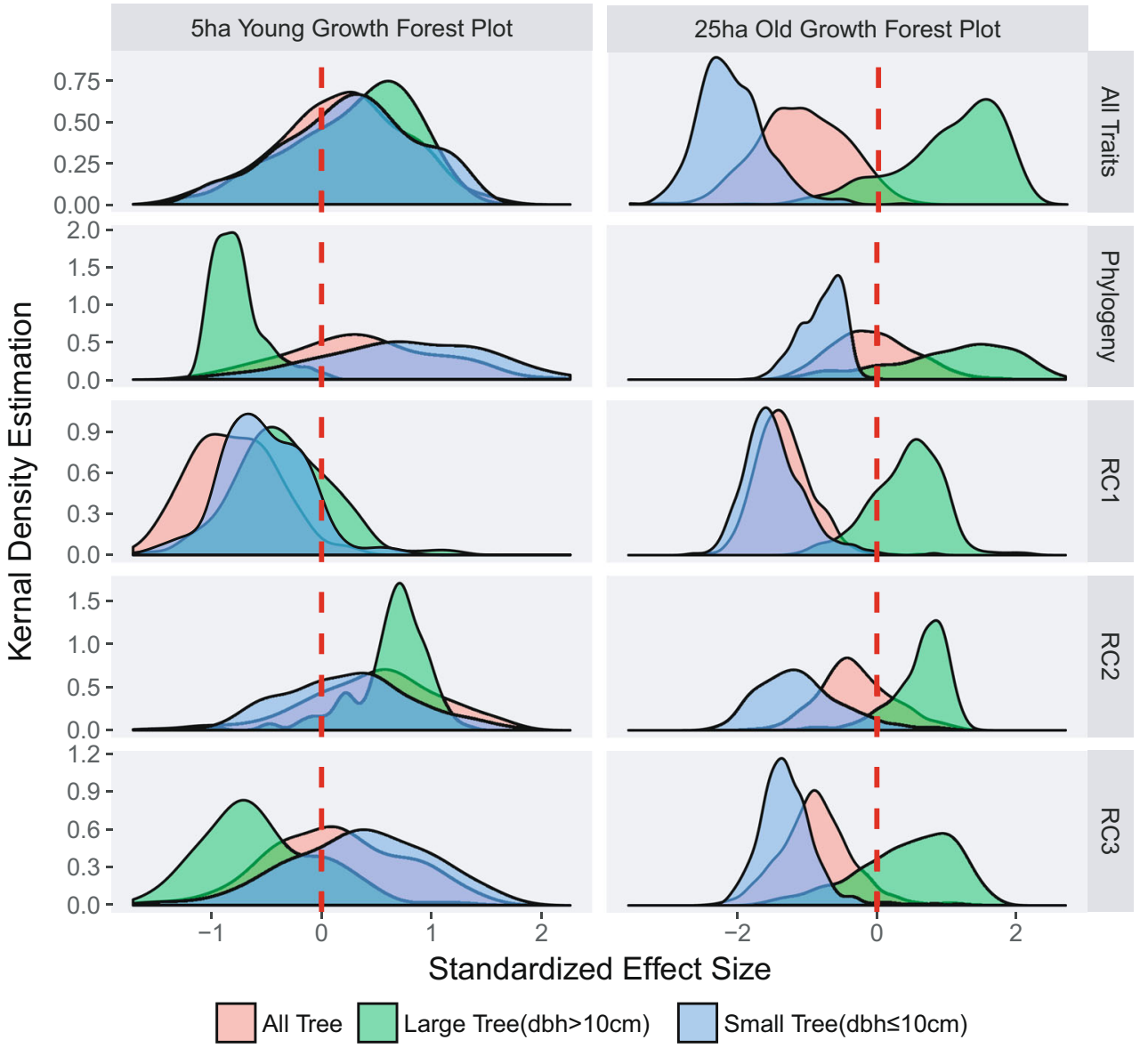

growth forest) from small to large trees. A similar result was also found when analyzing the three trait dimensions and phylogenetic change in both forests (Fig. 3).

\section{Discussion}

\subsection{Do deterministic processes drive temporal change in communities?}

Our study revealed that deterministic processes drove local functional and phylogenetic temporal changes in two temperate forests at different successional stages. In the younggrowth forest, we found that the temporal change was higher than expected, suggesting that species replacement involved functionally and phylogenetically dissimilar individuals. Over the first decades of succession, fast-growing pioneers could be progressively replaced by later-successional species with a resource conservative strategy, so that both the functional traits and phylogenetic difference among pioneers and latersuccessional species could contribute to the temporal change in the young-growth forest (Appendix S4) (Finegan 1996; Norden et al. 2012). However, the temporal change differed among trait dimensions, suggesting that assembly processes played differently on distinct facets of plant ecological strategies (Cornwell and Ackerly 2009; Herben and Goldberg 2014; Swenson and Enquist 2009). Specifically, we found that the temporal change was higher than expected along the stem trait dimension. The stem trait dimension is more related to structural traits (e.g., height and wood density) and can reflect species' mechanical resistance, water transport, and light competition ability (Chave et al. 2009; Iida et al. 2012). Therefore, the directional filtering of species with different resistance and competition abilities over time could drive the composition change (Craven et al. 2015; Raevel et al. 2012). The prevalence of deterministic process was also supported by the results of two size classes, suggesting that directional filtering played on trees of different sizes along the stem dimension. In contrast, the temporal changes did not show a significant departure from random expectation along the root dimension based on all trees. One possible explanation is that opposite patterns among size classes could counterbalance each other.

In the old-growth forest, the functional temporal change was lower than expected, supporting the idea that functional composition in the old-growth community could reach some steady state (Drury and Nisbet 1973; Li et al. 2016; Magurran and Henderson 2010). However, we found dissimilar patterns across size classes; i.e., change was higher 
Fig. 2 Relative contributions of abiotic and biotic factors to functional and phylogenetic temporal changes of all trees based on the boosted regression tree (BRT) models. Pie charts show the relative influences of biotic factors, topographic factors, and soil factors. SD, stem density per square meter; SR, species richness for each 400- $\mathrm{m}^{2}$ quadrat; $\mathrm{BA}$, basal area $\left(\mathrm{m}^{2}\right)$ for each 400 $\mathrm{m}^{2}$ quadrat; SLO, slope; ELE, elevation; ASP, aspect; Soill and Soil2, the first and second principal components of soil factors 5ha Young Growth Forest Plot
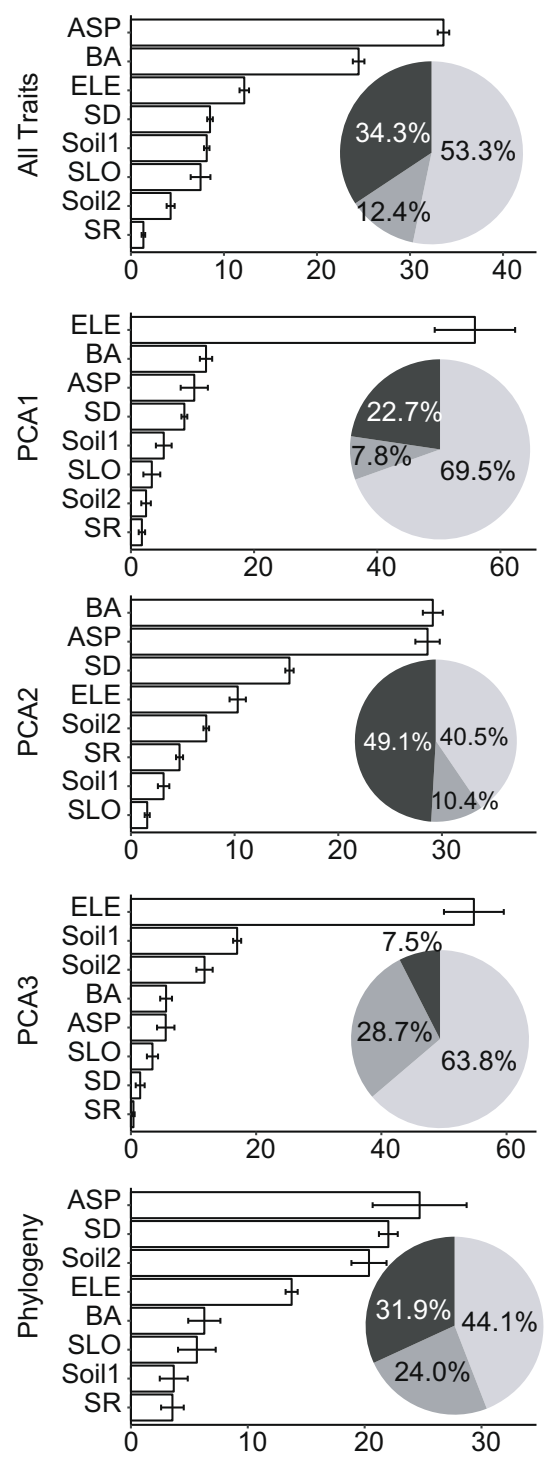

Relative Contribution(\%)

Biotic factors 25ha Old Growth Forest Plot
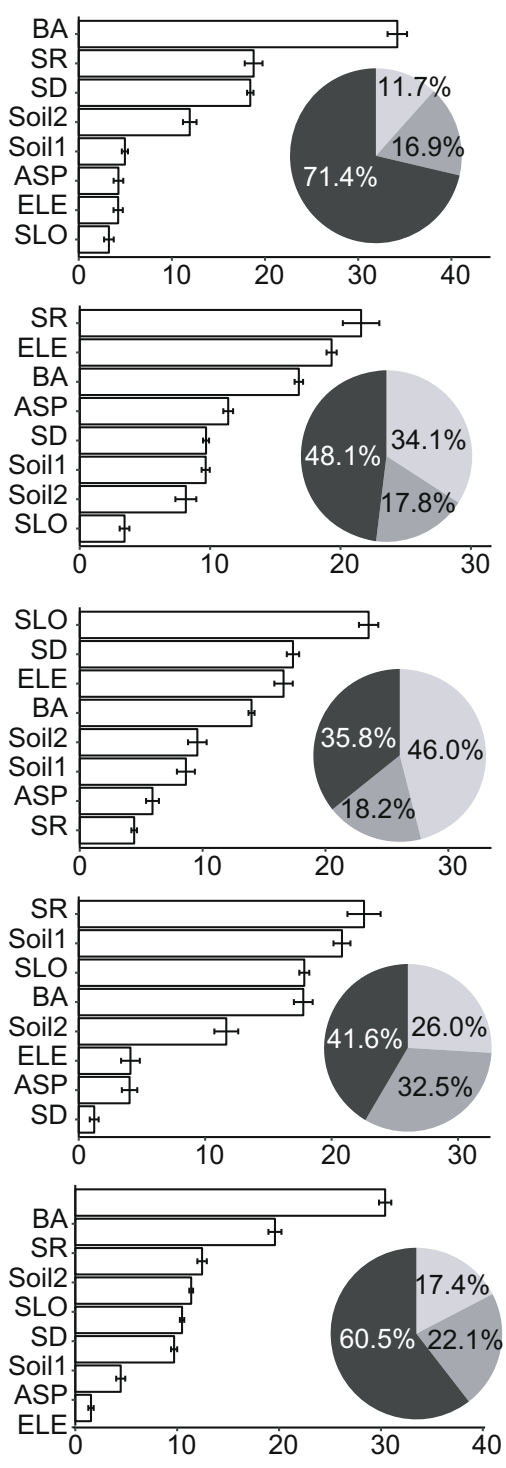

Soil than expected for large trees and lower than expected for small trees. While environmental filtering could more strongly constrain the dynamics of smaller trees, competition for available resources could induce a niche differentiation among trees reaching the canopy and thus affect the temporal change among large trees (Lasky et al. 2015). Here, a higher temporal change reflected the replacement of individuals by functionally and/or phylogenetically more dissimilar individuals and was consistent with an influence of limiting similarity due to competition (Swenson et al. 2007). Furthermore, a higher temporal change of large trees was consistently found for the three trait dimensions. Since separate functional dimensions can convey complementary insights on niche-based dynamics (Kraft et al. 2015; Raevel et al. 2012), we can infer that the replacement of large trees involved a niche differentiation in the old-growth forest at least along the three basic dimensions found in our survey.

Phylogenetic information can be regarded as a synthetic measure of species ecological dissimilarity, and examining a phylogenetic pattern can provide additional information that has not been provided by patterns of functional traits (Gerhold et al. 2015; Mouquet et al. 2012). Here, we found unmatched or even opposite functional and phylogenetic patterns, as in some previous studies (Cadotte et al. 2017; Purschke et al. 2013). Most functional traits here had low phylogenetic signal, and both functional and phylogenetic patterns were often nonrandom, suggesting that both measured and unmeasured traits could influence community 
5ha Young Growth Forest Plot

Small Trees
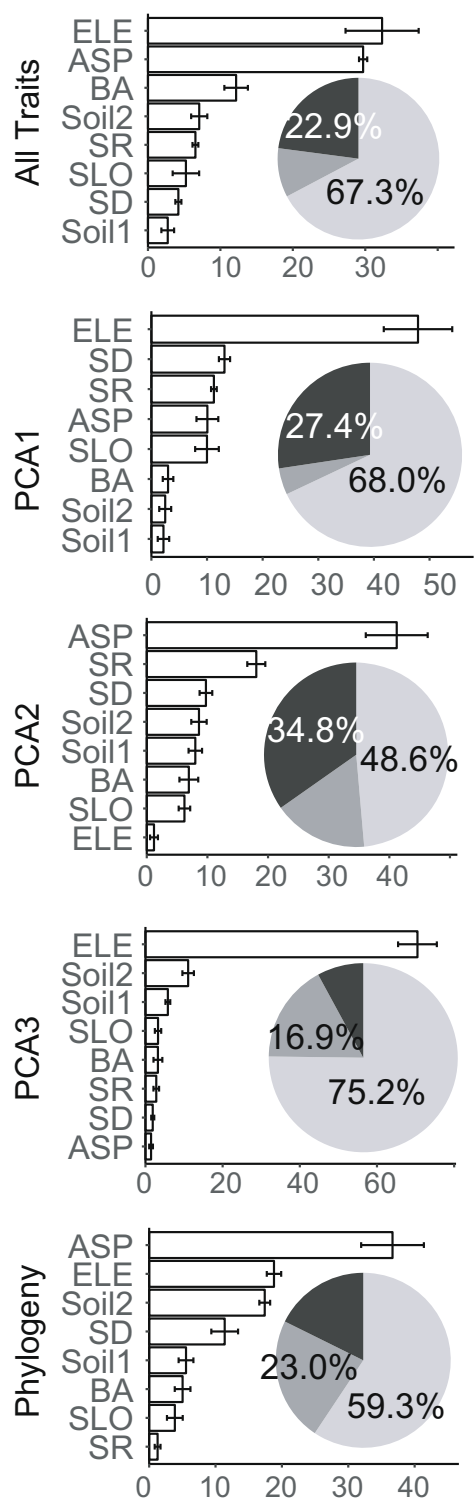

Large Trees
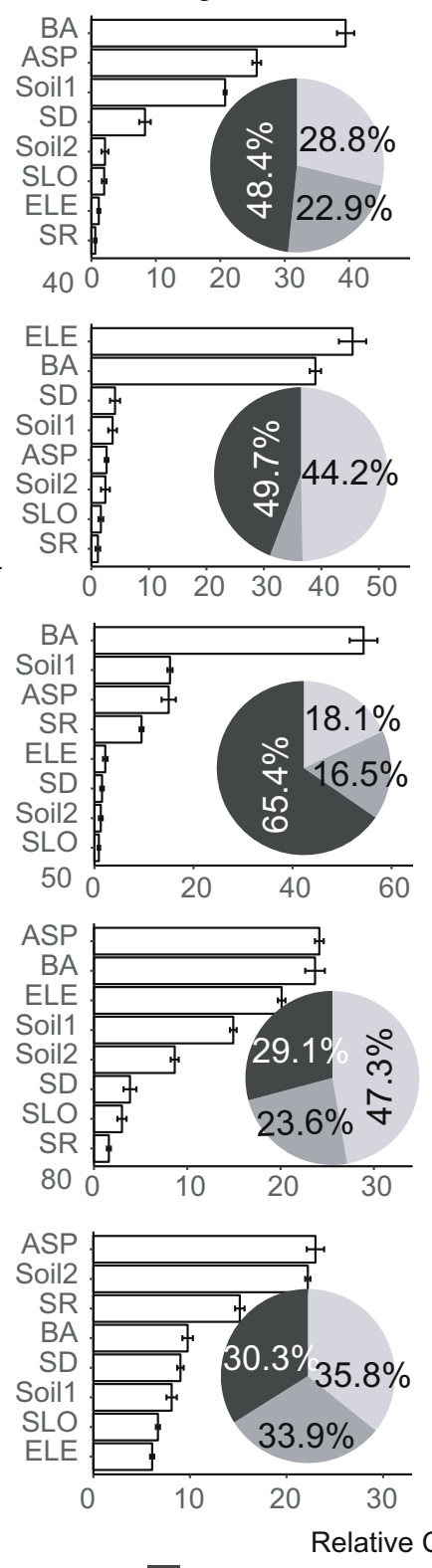

25ha Old Growth Forest Plot
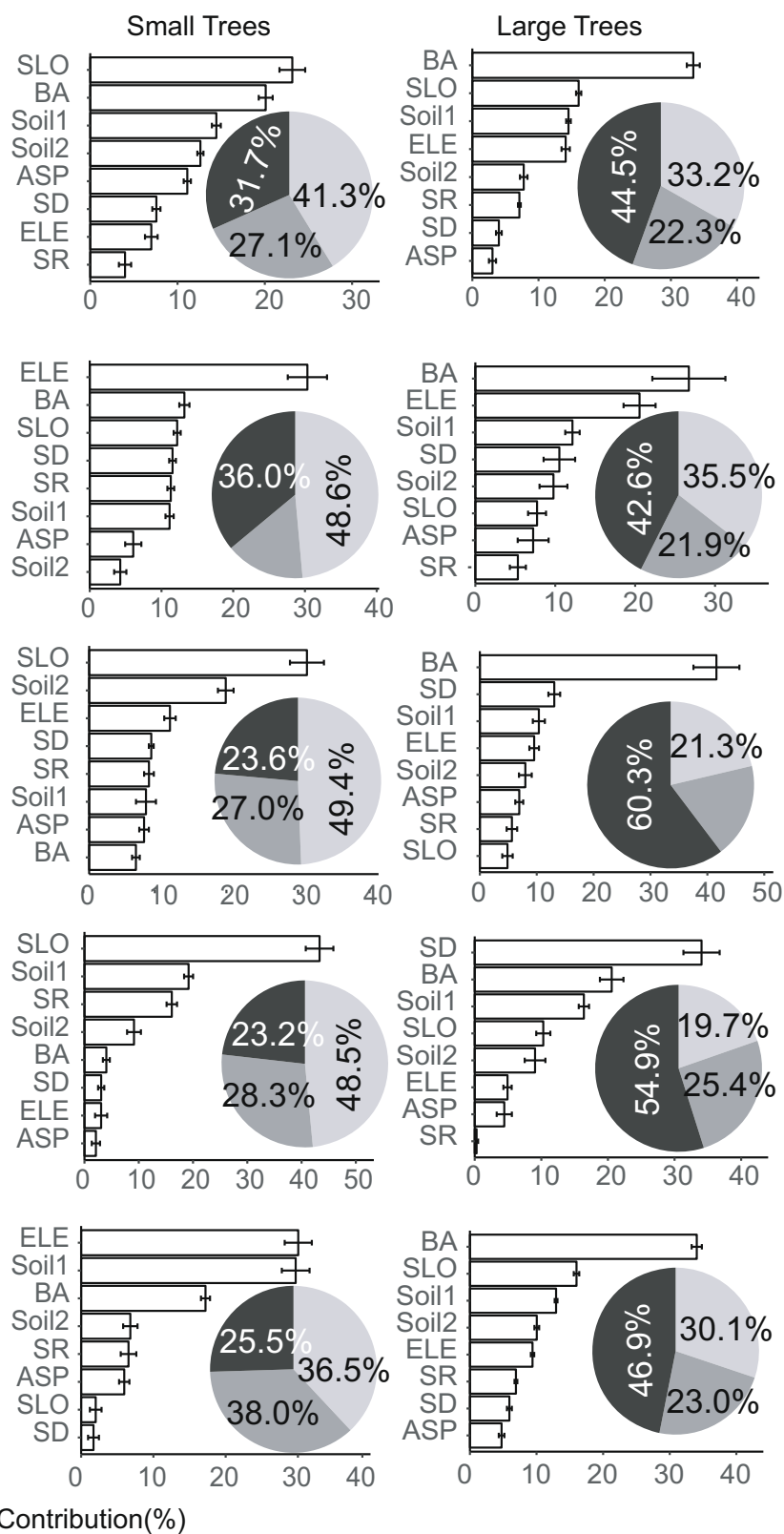

Biotic factors

Soil

Topography

Fig. 3 Relative contributions of environmental factors to functional and phylogenetic changes of different size trees based on the boost regression tree (BRT) models. Pie charts show the summed relative influences of biotic factors, topographic factors, and soil factors. Same abbreviations as in Fig. 2

dynamics. Further study will be needed to identify which traits are more involved in community dynamics.

\subsection{How do abiotic and biotic factors influence temporal change?}

We found that the temporal change was generally driven by abiotic factors in the young-growth forest and by biotic factors in the old-growth forest, which suggested that dominant deterministic processes change from habitat filtering to limiting similarity and competition along succession (Connell and Slatyer 1977; Purschke et al. 2013). There has been extensive debate about whether there was a shift from habitat filtering to limiting similarity during succession (Bhaskar et al. 2014; Meiners et al. 2015). Here, our study provides novel insights into the drivers of functional and phylogenetic temporal changes in a temperate forest over more than 300 years. 
Abiotic factors, especially topography, drove functional and phylogenetic temporal changes in the young-growth forest, supporting the role of abiotic environmental filtering and the predictions of resource-driven succession models (Bazzaz and Pickett 1980; Finegan 1996). Shifting resource availability could directionally select species with particular resource use and growth strategies and thus influence temporal change by determining species survival and recruitment (Deák et al. 2015; Lebrija-Trejos et al. 2010; Liu et al. 2014; PunchiManage et al. 2013). Topography could be influential as it reflected microhabitat heterogeneity and fine-scale variations in soil nutrient, water, and light availability, so that it had consistent influence on temporal change along the primary trait dimensions (Brown et al. 2013). In this study, we also included soil factors as a potential abiotic driver of temporal change and found that it had certain influence on temporal changes along the root trait dimension. That could be mainly because the root trait dimension was more related to absorption of both water and nutrients from the soil (Bardgett et al. 2014). In order to more precisely assess the role of soil resources and abiotic conditions, direct measurement of other soil chemicalphysical properties should be performed in the future.

Noticeably, when we focused on the two distinct size classes, there was a directional change of the influential factors from abiotic to biotic across tree size classes in the young-growth forest. This agrees with the idea that the dominant processes change from habitat filtering to competition as tree grows (Baldeck et al. 2013; Swenson et al. 2007). Larger and older trees represent a subset of adapted trees after filtering in earlier ontogenetic stages, so that competition for space, soil nutrients, or light becomes a prominent force driving temporal change (Russo et al. 2005; Zangaro et al. 2008). Such competition could penalize the survival and recruitment of conspecific individuals, favoring the recruitment of trees from dissimilar species, so that the biotic context (e.g., basal area) could entail greater functional change for large trees (Zhu et al. 2015).

Biotic factors mostly contributed to temporal change in the old-growth forest ( $>300$ years old), supporting the idea that tree competition more and more contributed to the community assembly as succession went on (Acker et al. 2015; Macarthur and Levins 1967; Wills et al. 2016). In this oldgrowth forest, neighborhood interaction has been shown to be crucial for species survival and growth (Wang et al. 2012; Zhang et al. 2016). Here, our results further suggest that the filtering of more similar smaller trees (lower temporal change) could be more related to abiotic factors, while the replacement of large trees by more dissimilar ones (higher temporal change) could be more related to the biotic context. This suggested that the forest density entails environmental constraints selecting adapted strategies in the understory, while more dissimilar trees are more likely to reach the canopy under the influence of competition.

\subsection{Limitations}

Our research provides a comprehensive survey of how deterministic and stochastic processes influenced functional and phylogenetic temporal changes in a temperate forest ecosystem. However, there are a few key limitations to highlight. First, the present work evaluated community temporal change in two large temperate forest plots, which only represented two successional stages. Sampling more successional stages should provide further insights into how deterministic processes change over time. Second, the time interval considered here was quite short compared to the lifespan of trees and to the time needed for full replacement of trees in the forest community. Further study based on a longer timescale should provide stronger tests of the underlying mechanisms causing community changes during succession.

\section{Conclusion}

In our study, we highlighted the dominance of deterministic process driving community functional and phylogenetic temporal changes over succession and across size classes. The dominant factors underlying temporal changes shifted from abiotic (especially for topographic factors) to biotic factors across successional stage and with increasing tree size. In summary, our research provides important evidence about the mechanisms underlying functional and phylogenetic temporal changes in temperate forests.

Acknowledgements We are grateful to the CBS plots census and data management teams and the funding sources that enabled field censuses at these sites. We would also like to thank Marc Cadotte at the University of Toronto, Fons van der Plas at the University of Leipzig, and Craig E. Martin at the University of Kansas for their review of the manuscript and constructive comments.

Funding This work was supported by the Strategic Priority Research Program of the Chinese Academy of Sciences (XDB31030000), the National Natural Science Foundation of China (31722010, 31770666, and 31670632), and the Key Research Program of Frontier Sciences, Chinese Academy of Sciences (QYZDB-SSW-DQC002), K.C. Wong Education Foundation, and the open fund of the Changbai Mountain Academy of Sciences.

Data availability The datasets generated during and/or analyzed during the current study are available from the corresponding author on reasonable request.

\section{Compliance with ethical standards}

Conflict of interest The authors declare that they have no conflict of interest. 


\section{References}

Acker SA, Boetsch JR, Bivin M, Whiteaker L, Cole C, Philippi T (2015) Recent tree mortality and recruitment in mature and old-growth forests in Western Washington. For Ecol Manag 336:109-118. https://doi.org/10.1016/j.foreco.2014.10.008

Adler PB, Fajardo A, Kleinhesselink AR, Kraft NJ (2013) Trait-based tests of coexistence mechanisms. Ecol Lett 16:1294-1306. https:// doi.org/10.1111/ele.12157

Alday JG, Marrs RH, Martinez-Ruiz C (2011) Vegetation convergence during early succession on coal wastes: a 6-year permanent plot study. J Veg Sci 22:1072-1083. https://doi.org/10.1111/j.16541103.2011.01308.x

Anderson KJ (2007) Temporal patterns in rates of community change during succession. Am Nat 169:780-793. https://doi.org/10.1086/516653

Baldeck CA, Harms KE, Yavitt JB, John R, Turner BL, Valencia R, Navarrete H, Bunyavejchewin S, Kiratiprayoon S, Yaacob A, Supardi MNN, Davies SJ, Hubbell SP, Chuyong GB, Kenfack D, Thomas DW, Dalling JW (2013) Habitat filtering across tree life stages in tropical forest communities. Proc R Soc Lond B Biol Sci 280:20130548. https://doi.org/10.1098/rspb.2013.0548

Bardgett RD, Mommer L, De Vries FT (2014) Going underground: root traits as drivers of ecosystem processes. Trends Ecol Evol 29:692699. https://doi.org/10.1016/j.tree.2014.10.006

Bazzaz F, Pickett S (1980) Physiological ecology of tropical succession: a comparative review. Annu Rev Ecol Syst 11:287-310. https://doi. org/10.1146/annurev.es.11.110180.001443

Bestová H, Munoz F, Svoboda P, Škaloud P, Violle C (2018) Ecological and biogeographical drivers of freshwater green algae biodiversity: from local communities to large-scale species pools of desmids. Oecologia 186:1017-1030. https://doi.org/10.1007/s00442-018-4074-x

Bhaskar R, Dawson TE, Balvanera P (2014) Community assembly and functional diversity along succession post-management. Funct Ecol 28:1256-1265. https://doi.org/10.1111/1365-2435.12257

Blomberg SP, Garland T, Ives AR (2003) Testing for phylogenetic signal in comparative data: behavioral traits are more labile. Evolution 57: 717-745. https://doi.org/10.1554/0014-3820(2003)057[0717: TFPSIC]2.0.CO;2

Brown C, Burslem DFRP, Illian JB, Bao L, Brockelman W, Cao M, Chang LW, Dattaraja HS, Davies S, Gunatilleke CVS, Gunatilleke IAUN, Huang J, Kassim AR, LaFrankie JV, Lian J, Lin L, Ma K, Mi X, Nathalang A, Noor S, Ong P, Sukumar R, Su SH, Sun IF, Suresh HS, Tan S, Thompson J, Uriarte M, Valencia R, Yap SL, Ye W, Law R (2013) Multispecies coexistence of trees in tropical forests: spatial signals of topographic niche differentiation increase with environmental heterogeneity. Proc R Soc Lond B Biol Sci 280:20130502. https://doi.org/10.1098/rspb.2013.0502

Cadotte MW, Carscadden K, Mirotchnick N (2011) Beyond species: functional diversity and the maintenance of ecological processes and services. J Appl Ecol 48:1079-1087. https://doi.org/10.1111/j. 1365-2664.2011.02048.x

Cadotte M, Albert CH, Walker SC (2013) The ecology of differences: assessing community assembly with trait and evolutionary distances. Ecol Lett 16:1234-1244. https://doi.org/10.1111/ele.12161

Cadotte MW, Davies TJ, Peres-Neto PR (2017) Why phylogenies do not always predict ecological differences. Ecol Monogr 87:535-551. https://doi.org/10.1002/ecm.1267

Canham CD, LePage PT, Coates KD (2004) A neighborhood analysis of canopy tree competition: effects of shading versus crowding. Can J For Res 34:778-787. https://doi.org/10.1139/x03-232

Cequinel A, Capellesso ES, Marcilio-Silva V, Cardoso FC, Marques MC (2018) Determinism in tree turnover during the succession of a tropical forest. Perspec Plant Ecol Evol Syst 34:120-128. https:// doi.org/10.1016/j.ppees.2018.08.007
Chave J, Coomes D, Jansen S, Lewis SL, Swenson NG, Zanne AE (2009) Towards a worldwide wood economics spectrum. Ecol Lett 12:351366. https://doi.org/10.1111/j.1461-0248.2009.01285.x

Connell JH, Slatyer RO (1977) Mechanisms of succession in natural communities and their role in community stability and organization. Am Nat 111:1119-1144. https://doi.org/10.1086/283241

Cornwell WK, Ackerly DD (2009) Community assembly and shifts in plant trait distributions across an environmental gradient in coastal. California. Ecol Monogr 79:109-126. https://doi.org/10.1890/071134.1

Craven D, Hall JS, Berlyn GP, Ashton MS, van Breugel M (2015) Changing gears during succession: shifting functional strategies in young tropical secondary forests. Oecologia 179:293-305. https:// doi.org/10.1007/s00442-015-3339-x

Deák B, Valkó O, Török P, Kelemen A, Miglécz T, Szabó S, Szabó G, Tóthmérész B (2015) Micro-topographic heterogeneity increases plant diversity in old stages of restored grasslands. Basic Appl Ecol 16:291-299. https://doi.org/10.1016/j.baae.2015.02.008

Díaz S, Kattge J, Cornelissen JHC, Wright IJ, Lavorel S, Dray S, Reu B, Kleyer M, Wirth C, Colin Prentice I, Garnier E, Bönisch G, Westoby M, Poorter H, Reich PB, Moles AT, Dickie J, Gillison AN, Zanne AE, Chave J, Joseph Wright S, Sheremet'ev SN, Jactel H, Baraloto C, Cerabolini B, Pierce S, Shipley B, Kirkup D, Casanoves F, Joswig JS, Günther A, Falczuk V, Rüger N, Mahecha MD, Gorné LD (2016) The global spectrum of plant form and function. Nature 529:167-171. https://doi.org/10.1038/nature16489

Dornelas M, Magurran AE, Buckland ST, Chao A, Chazdon RL, Colwell RK, Curtis T, Gaston KJ, Gotelli NJ, Kosnik MA, McGill B, McCune JL, Morlon H, Mumby PJ, Ovreas L, Studeny A, Vellend M (2013) Quantifying temporal change in biodiversity: challenges and opportunities. Proc R Soc Lond B Biol Sci 280:20121931. https://doi.org/10.1098/rspb.2012.1931

Dray S, Pélissier R, Couteron P, Fortin MJ, Legendre P, Peres-Neto PR, Bellier E, Bivand R, Blanchet FG, de Cáceres M, Dufour AB, Heegaard E, Jombart T, Munoz F, Oksanen J, Thioulouse J, Wagner HH (2012) Community ecology in the age of multivariate multiscale spatial analysis. Ecol Monogr 82:257-275. https://doi. org/10.1890/11-1183.1

Drury WH, Nisbet ICT (1973) Succession. J Arnold Arboretum $54: 331-368$

Elith J, Leathwick JR, Hastie T (2008) A working guide to boosted regression trees. J Anim Ecol 77:802-813. https://doi.org/10.1111/j. 1365-2656.2008.01390.x

Finegan B (1996) Pattern and process in Neotropical secondary rain forests: the first 100 years of succession. Trends Ecol Evol 11:119-124. https://doi.org/10.1016/0169-5347(96)81090-1

Gerhold P, Cahill JF, Winter M, Bartish IV, Prinzing A (2015) Phylogenetic patterns are not proxies of community assembly mechanisms (they are far better). Funct Ecol 29:600-614. https://doi.org/ $10.1111 / 1365-2435.12425$

Gianuca AT, Declerck SA, Cadotte MW, Souffreau C, Bie T, Meester L (2017) Integrating trait and phylogenetic distances to assess scaledependent community assembly processes. Ecography 40:742-752. https://doi.org/10.1111/ecog.02263

Gotelli NJ (2000) Null model analysis of species co-occurrence patterns. Ecology 81:2606-2621. https://doi.org/10.1890/00129658(2000)081[2606:Nmaosc]2.0.Co;2

Götzenberger L, de Bello F, Bråthen KA, Davison J, Dubuis A, Guisan A, Lepš J, Lindborg R, Moora M, Pärtel M, Pellissier L, Pottier J, Vittoz P, Zobel K, Zobel M (2012) Ecological assembly rules in plant communities - approaches, patterns and prospects. Biol Rev 87:111-127. https://doi.org/10.1111/j.1469-185X.2011.00187.x

Hao Z, Zhang J, Song B, Ye J, Li B (2007) Vertical structure and spatial associations of dominant tree species in an old-growth temperate forest. For Ecol Manag 252:1-11. https://doi.org/10.1016/j.foreco. 2007.06.026 
Herben T, Goldberg DE (2014) Community assembly by limiting similarity vs. competitive hierarchies: testing the consequences of dispersion of individual traits. J Ecol 102:156-166. https://doi.org/10. $1111 / 1365-2745.12181$

Hubbell SP (2001) The unified neutral theory of biodiversity and biogeography (MPB-32), vol 32. Princeton University Press

Iida Y, Poorter L, Sterck FJ, Kassim AR, Kubo T, Potts MD, Kohyama TS (2012) Wood density explains architectural differentiation across 145 co-occurring tropical tree species. Funct Ecol 26:274-282. https://doi.org/10.1111/j.1365-2435.2011.01921.x

Jabot $\mathrm{F}$ et al (2018) Assessing metacommunity processes through signatures in spatiotemporal turnover of community composition. bioRxiv:480335

Kembel SW, Cowan PD, Helmus MR, Cornwell WK, Morlon H, Ackerly DD, Blomberg SP, Webb CO (2010) Picante: R tools for integrating phylogenies and ecology. Bioinformatics 26:1463-1464. https://doi. org/10.1093/bioinformatics/btq166

Kraft NJ, Godoy O, Levine JM (2015) Plant functional traits and the multidimensional nature of species coexistence. Proc Natl Acad Sci 112:797-802. https://doi.org/10.1073/pnas.1413650112

Kramer-Walter KR, Bellingham PJ, Millar TR, Smissen RD, Richardson SJ, Laughlin DC (2016) Root traits are multidimensional: specific root length is independent from root tissue density and the plant economic spectrum. J Ecol 104:1299-2310. https://doi.org/10. $1111 / 1365-2745.12562$

Lasky JR, Bachelot B, Muscarella R, Schwartz N, Forero-Montaña J, Nytch CJ, Swenson NG, Thompson J, Zimmerman JK, Uriarte M (2015) Ontogenetic shifts in trait-mediated mechanisms of plant community assembly. Ecology 96:2157-2169. https://doi.org/10. 1890/14-1809.1.sm

Laughlin DC (2014) The intrinsic dimensionality of plant traits and its relevance to community assembly. J Ecol 102:186-193. https://doi. org/10.1111/1365-2745.12187

Lebrija-Trejos E, Pérez-García EA, Meave JA, Bongers F, Poorter L (2010) Functional traits and environmental filtering drive community assembly in a species-rich tropical system. Ecology 91:386398. https://doi.org/10.1890/08-1449.1

Legendre P, Gauthier O (2014) Statistical methods for temporal and spacetime analysis of community composition data. Proc R Soc Lond B Biol Sci 281:20132728. https://doi.org/10.1098/rspb.2013.2728

Letten AD, Keith DA, Tozer MG (2014) Phylogenetic and functional dissimilarity does not increase during temporal heathland succession. Proc R Soc Lond B Biol Sci 281:20142102. https://doi.org/ 10.1098/rspb.2014.2102

Li SP, Cadotte MW, Meiners SJ, Hua ZS, Jiang L, Shu WS (2015) Species colonisation, not competitive exclusion, drives community overdispersion over long-term succession. Ecol Lett 18:964-973. https://doi.org/10.1111/ele.12476

Li SP, Cadotte MW, Meiners SJ, Pu ZC, Fukami T, Jiang L (2016) Convergence and divergence in a long-term old-field succession: the importance of spatial scale and species abundance. Ecol Lett 19:1101-1109. https://doi.org/10.1111/ele.12647

Li LP, Cadotte MW, Martinez-Garza C, de la Pena-Domene M, Du GZ (2018) Planting accelerates restoration of tropical forest but assembly mechanisms appear insensitive to initial composition. J Appl Ecol 55:986-996. doi:https://doi.org/10.1111/1365-2664.12976

Liu J, Yunhong T, Slik JF (2014) Topography related habitat associations of tree species traits, composition and diversity in a Chinese tropical forest. For Ecol Manag 330:75-81. https://doi.org/10.1016/j.foreco. 2014.06.045

Lohbeck M, Poorter L, Martínez-Ramos M, Rodriguez-Velázquez J, Breugel M, Bongers F (2014) Changing drivers of species dominance during tropical forest succession. Funct Ecol 28:1052-1058. https://doi.org/10.1111/1365-2435.12240
Macarthur R, Levins R (1967) Limiting similarity convergence and divergence of coexisting species. Am Nat 101:377-385. https://doi. org/10.1086/282505

Magurran AE, Henderson PA (2010) Temporal turnover and the maintenance of diversity in ecological assemblages. Philos Trans R Soc B: Biol Sci 365:3611-3620. https://doi.org/10.1098/rstb.2010.0285

Meiners SJ, Cadotte MW, Fridley JD, Pickett ST, Walker LR (2015) Is successional research nearing its climax? New approaches for understanding dynamic communities. Funct Ecol 29:154-164. https:// doi.org/10.1111/1365-2435.12391

Mouquet N, Devictor V, Meynard CN, Munoz F, Bersier LF, Chave J, Couteron P, Dalecky A, Fontaine C, Gravel D, Hardy OJ, Jabot F, Lavergne S, Leibold M, Mouillot D, Münkemüller T, Pavoine S, Prinzing A, Rodrigues ASL, Rohr RP, Thébault E, Thuiller W (2012) Ecophylogenetics: advances and perspectives. Biol Rev 87: 769-785. https://doi.org/10.1111/j.1469-185X.2012.00224.x

Norden N, Letcher SG, Boukili V, Swenson NG, Chazdon R (2012) Demographic drivers of successional changes in phylogenetic structure across life-history stages in plant communities. Ecology 93: S70-S82. https://doi.org/10.1890/10-2179.1

Pérez-Harguindeguy N, Díaz S, Garnier E, Lavorel S, Poorter H, Jaureguiberry P, Bret-Harte MS, Cornwell WK, Craine JM, Gurvich DE, Urcelay C, Veneklaas EJ, Reich PB, Poorter L, Wright IJ, Ray P, Enrico L, Pausas JG, de Vos AC, Buchmann N, Funes G, Quétier F, Hodgson JG, Thompson K, Morgan HD, ter Steege H, Sack L, Blonder B, Poschlod P, Vaieretti MV, Conti G, Staver AC, Aquino S, Cornelissen JHC (2013) New handbook for standardised measurement of plant functional traits worldwide. Aust J Bot 61:167-234. https://doi.org/10.1071/BT12225

Petchey OL, Gaston KJ (2007) Dendrograms and measuring functional diversity. Oikos 116:1422-1426. https://doi.org/10.1111/j.2007. 0030-1299.15894.x

Punchi-Manage R, Getzin S, Wiegand T, Kanagaraj R, Savitri Gunatilleke CV, Nimal Gunatilleke IAU, Wiegand K, Huth A (2013) Effects of topography on structuring local species assemblages in a Sri Lankan mixed dipterocarp forest. J Ecol 101:149 160. https://doi.org/10.1111/1365-2745.12017

Purschke O, Schmid BC, Sykes MT, Poschlod P, Michalski SG, Durka W, Kühn I, Winter M, Prentice HC (2013) Contrasting changes in taxonomic, phylogenetic and functional diversity during a long-term succession: insights into assembly processes. J Ecol 101:857-866. https://doi.org/10.1111/1365-2745.12098

Raevel V, Violle C, Munoz F (2012) Mechanisms of ecological succession: insights from plant functional strategies. Oikos 121:17611770. https://doi.org/10.1111/j.1600-0706.2012.20261.x

Reich PB (2014) The world-wide 'fast-slow' plant economics spectrum: a traits manifesto. J Ecol 102:275-301. https://doi.org/10.1111/ $1365-2745.12211$

Rüger N, Wirth C, Wright SJ, Condit R (2012) Functional traits explain light and size response of growth rates in tropical tree species. Ecology 93:2626-2636. https://doi.org/10.1890/12-0622.1

Russo SE, Davies SJ, King DA, Tan S (2005) Soil-related performance variation and distributions of tree species in a Bornean rain forest. J Ecol 93:879-889. https://doi.org/10.1111/j.1365-2745.2005.01030.x

Shimadzu H, Dornelas M, Magurran AE (2015) Measuring temporal turnover in ecological communities. Methods Ecol Evol 6:1384 1394. https://doi.org/10.1111/2041-210X.12438

Stegen JC, Freestone AL, Crist TO, Anderson MJ, Chase JM, Comita LS, Cornell HV, Davies KF, Harrison SP, Hurlbert AH, Inouye BD, Kraft NJB, Myers JA, Sanders NJ, Swenson NG, Vellend M (2013) Stochastic and deterministic drivers of spatial and temporal turnover in breeding bird communities. Glob Ecol Biogeogr 22: 202-212. https://doi.org/10.1111/j.1466-8238.2012.00780.x

Suo Y, Yuan Z, Lin F, Wang X, Ye J, Bai E, Hao Z (2016) Local-scale determinants of elemental stoichiometry of soil in an old-growth 
temperate forest. Plant Soil 408:401-414. https://doi.org/10.1007/ s11104-016-2939-5

Swenson NG (2013) The assembly of tropical tree communities - the advances and shortcomings of phylogenetic and functional trait analyses. Ecography 36:264-276. https://doi.org/10.1111/j.16000587.2012.00121.x

Swenson NG, Enquist BJ (2009) Opposing assembly mechanisms in a Neotropical dry forest: implications for phylogenetic and functional community ecology. Ecology 90:2161-2170. https://doi.org/10. 1890/08-1025.1

Swenson NG, Enquist BJ, Thompson J, Zimmerman JK (2007) The influence of spatial and size scale on phylogenetic relatedness in tropical forest communities. Ecology 88:1770-1780. https://doi. org/10.1890/06-1499.1

Swenson NG, Enquist BJ, Thompson J, Zimmerman JK (2012) Temporal turnover in the composition of tropical tree communities: functional determinism and phylogenetic stochasticity. Ecology 93:490-499. https://doi.org/10.1890/06-1499.1

Wang X, Comita LS, Hao Z, Davies SJ, Ye J, Lin F, Yuan Z (2012) Localscale drivers of tree survival in a temperate forest. PLoS One 7: e29469. https://doi.org/10.1371/journal.pone.0029469

Wang X, Wiegand T, Swenson NG, Wolf AT, Howe RW, Hao Z, Lin F, Ye J, Yuan Z (2015) Mechanisms underlying local functional and phylogenetic beta diversity in two temperate forests. Ecology 96:1062 1073. https://doi.org/10.1890/14-0392.1

Webb CO, Donoghue MJ (2005) Phylomatic: tree assembly for applied phylogenetics. Mol Ecol Notes 5:181-183. https://doi.org/10.1111/j. 1471-8286.2004.00829.x

Webb CO, Ackerly DD, McPeek MA, Donoghue MJ (2002) Phylogenies and community ecology. Annu Rev Ecol Syst 33:475-505. https:// doi.org/10.1146/annurev.ecolysis.33.010802.150448

Westoby M, Falster DS, Moles AT, Vesk PA, Wright IJ (2002) Plant ecological strategies: some leading dimensions of variation between species. Annu Rev Ecol Syst 33:125-159. https://doi.org/10.1146/ annurev.ecolsys.33.010802.150452

Wills C, Harms KE, Wiegand T, Punchi-Manage R, Gilbert GS, Erickson D, Kress WJ, Hubbell SP, Gunatilleke CVS, Gunatilleke IAUN (2016) Persistence of neighborhood demographic influences over long phylogenetic distances may help drive post-speciation adaptation in tropical forests. PLoS One 11:e0156913. https://doi.org/10. 1371/journal.pone.0156913
Yang H, Li D, Wang B, Han J (1985) Distribution patterns of dominant tree species on northern slope of Changbai Mountain (in Chinese). Res For Ecosyst 5:1-14

Yang J, Zhang G, Ci X, Swenson NG, Cao M, Sha L, Li J, Baskin CC, Slik JWF, Lin L (2014) Functional and phylogenetic assembly in a Chinese tropical tree community across size classes, spatial scales and habitats. Funct Ecol 28:520-529. https://doi.org/10.1111/13652435.12176

Zangaro W, de Assis RL, Rostirola LV, de Souza PB, Gonçalves MC, Andrade G, Nogueira MA (2008) Changes in arbuscular mycorrhizal associations and fine root traits in sites under different plant successional phases in Southern Brazil. Mycorrhiza 19:37-45. https://doi.org/10.1007/s00572-008-0202-5

Zanne AE, Tank DC, Cornwell WK, Eastman JM, Smith SA, FitzJohn RG, McGlinn DJ, O'Meara BC, Moles AT, Reich PB, Royer DL, Soltis DE, Stevens PF, Westoby M, Wright IJ, Aarssen L, Bertin RI, Calaminus A, Govaerts R, Hemmings F, Leishman MR, Oleksyn J, Soltis PS, Swenson NG, Warman L, Beaulieu JM (2014) Three keys to the radiation of angiosperms into freezing environments. Nature 506:89-92. https://doi.org/10.1038/nature12872

Zhang J, Huang S, He F (2015) Half-century evidence from Western Canada shows forest dynamics are primarily driven by competition followed by climate. Proc Natl Acad Sci 112:4009-4014. https:// doi.org/10.1073/pnas.1420844112

Zhang Z, Papaik MJ, Wang X, Hao Z, Ye J, Lin F, Yuan Z (2016) The effect of tree size, neighborhood competition and environment on tree growth in an old-growth temperate forest. J Plant Ecol 10:970 980. https://doi.org/10.1093/jpe/rtw126

Zhang H, Chen HYH, Lian J, John R, Ronghua L, Liu H, Ye W, Berninger F, Ye Q (2018) Using functional trait diversity patterns to disentangle the scale-dependent ecological processes in a subtropical forest. Funct Ecol 32:1379-1389. https://doi.org/10.1111/13652435.13079

Zhu Y, Comita LS, Hubbell SP, Ma K (2015) Conspecific and phylogenetic density-dependent survival differs across life stages in a tropical forest. J Ecol 103:957-966. https://doi.org/10.1111/1365-2745.12414

Publisher's note Springer Nature remains neutral with regard to jurisdictional claims in published maps and institutional affiliations. 